\title{
CONDIÇÕES DE ACESSO A INFORMAÇÃO NO CONTEXTO DO POLO DE EDUCAÇÃO A DISTÂNCIA DA UNIVERSIDADE ABERTA DO BRASIL ${ }^{1}$
}

\author{
CONDITIONS OF ACCESS TO INFORMATION IN THE CONTEXT OF THE \\ DISTANCE EDUCATION POLICY OF THE UNIVERSITY OPEN BRAZIL
}

\section{CONDICIONES DE ACCESO A LA INFORMACIÓN EN EL CONTEXTO DE LA \\ POLÍTICA DE EDUCACIÓN A DISTANCIA DE LA UNIVERSIDAD ABIERTA BRASILULO}

Helena Cristina Pimentel do Vale ${ }^{2}$ Luis Paulo Mercado ${ }^{3}$ Fernando Silvio Cavalcante Pimentel ${ }^{4}$

Resumo: O trabalho do bibliotecário e sua inserção na equipe multidisciplinar da Universidade Aberta do Brasil (UAB) ainda é pouco debatido no âmbito das Instituições Públicas de Ensino Superior (IPES) participantes. Este artigo trata do bibliotecário no contexto do polo de Educação a Distância $(\mathrm{EaD})$ da UAB. Resulta de pesquisa que investigou a existência de bibliotecas, de serviços de acesso a informação oferecidos aos estudantes dos polos da UAB e a presença do bibliotecário nos polos atuando em conformidade com a legislação, os

\footnotetext{
${ }^{1}$ Submetido em: 03/10/2017 - Aceito em: 14/03/2018 - Publicado em: 28/02/2018

${ }^{2}$ Mestre em Educação (UFAL, 2015). Bibliotecária/documentalista da Universidade Federal de Alagoas. Tem experiência na área de Ciência da Informação, com ênfase em Biblioteconomia, atuando principalmente nos seguintes temas: Coordenação da Biblioteca de Teses e Dissertação da Universidade Federal de Alagoas (BDTD/UFAL), Catalogação na fonte, Indexação, Orientação sobre Normalização de Trabalhos Acadêmicos.

${ }^{3}$ Doutor em Educação (PUC/SP, 1998), Mestre em Educação (UFSM, 1993), Especialista em Formação de Professores em Mídias na Educação (UFAL, 2010), Graduado em Ciências Biológicas Licenciatura Plena (UFSM, 1989). Realizou aperfeiçoamento em Formação em Tutoria Online pela Organização dos Estados Americanos (OEA/INEAM) e em Melhoria da Qualidade da Educação pela UNESCO (UNESCO/OEA). É Professor Associado III vinculado ao Programa de Pós-Graduação em Educação da Universidade Federal de Alagoas. Lider do Grupo de Pesquisa Tecnologias da Informação e Comunicação na Formação de Professores Presencial e Online. ${ }^{4}$ Doutor em Educação (UFAL); Mestre em Educação pela Universidade Federal de Alagoas (2010), especialista em Tecnologias em Educação e Docência do Ensino Superior. Graduado em Pedagogia (Licenciatura) . Foi professor - de escolas particulares, tutor do programa de formação continuada - Secretaria de Educação a Distância - MEC, professor tutor 1 da Universidade Tiradentes e professor do Governo do Estado de Alagoas. Tem experiência na área de Educação, com ênfase em Ensino-Aprendizagem, atuando principalmente nos seguintes temas: aprendizagem, educação online, webquest, tutoria e avaliação. Atualmente é professor adjunto da Universidade Federal de Alagoas. Foi Vice-coordenador da Coordenadoria Institucional de Educação a Distância e Coordenador Adjunto da UAB/UFAL.
} 


\section{Revista Docência e Cibercultura}

Referenciais de Qualidade para o Ensino Superior a Distância (RQESD) e aos instrumentos de avaliação do Ministério da Educação (MEC). Identifica a oferta de serviços de acesso à informação oferecidos, pelas bibliotecas aos estudantes da UAB e conhece a atuação do bibliotecário nos polos da UAB. A coleta de dados ocorreu nas bibliotecas dos polos de EaD selecionados por amostragem a partir de informações fornecidas pelos Coordenadores de Polos, através de questionário disponibilizado online. Os resultados mostraram que as bibliotecas dos Polos da UAB, precisam se adequar ao modelo da EaD atualmente instituído no país para os cursos superiores a distância e pois não estão atendendo às necessidades dos estudantes da modalidade. Os resultados evidenciam que existe necessidade de instituir políticas públicas para garantir a implantação, manutenção e o funcionamento das bibliotecas em conformidade com a atual legislação. $\mathrm{O}$ estudo propõe sugestões de melhorias para adequar as bibliotecas dos polos às demandas dos estudantes dos cursos ofertados pela IPES. Propôs ações de caráter prático que possibilitem promover a melhoria das bibliotecas dos polos da UAB colaborando com os cursos existentes no Sistema UAB.

Palavras-chave: Bibliotecário; UAB; Polo de Apoio Presencial; Biblioteca; EaD

Abstract: The work of information professionals - librarians - and its role in the multidisciplinary team of UAB is still little discussed in the framework of the Public Institutions Higher Education participants. This research deals with the issue of librarian in the context of classroom support pole of the UAB. Its overall objective is to investigate if there are libraries, which provide access to information services offered students of Polos of UAB support and if there librarian at the poles acting in accordance with the proposal of UAB and Quality Benchmarks System for Higher Education and Distance the instruments of evaluation of the Ministry of Education, and specific objectives to identify which information access services are offered by libraries, student at the UAB and know the librarian's role in classroom support poles of the UAB. Initially it was necessary to increase knowledge of Distance Education, UAB and the relevant legislation to this educational modality in Brazil, to better understand and achieve the research objectives, relying on ad hoc support from UAB poles. To collect data from the libraries of the Centers for Classroom Support from information provided by the centers coordinators who were selected at random. To collect data, we opted for the questionnaire, available online and is considered appropriate for this research. Data were analyzed and interpreted considering the objectives of the libraries of classroom support poles of the UAB randomly selected. The results point to the conclusion that the libraries of Poles Support Face the UAB, have yet to suit ODL model currently established in the country for higher education distance and therefore are not meeting the needs of students. The results show that there is a need to establish public policies at state and municipal level to ensure the implementation, maintenance and operation of libraries in accordance with the current legislation. This study proposes suggestions for improvements to suit the libraries of the poles to the demands of the students of the courses offered by IPES.

Keywords: Librarian; Open University of Brazil; Poles Support Classroom; Library. Distance learning.

Resumen: El trabajo de los profesionales de la información - bibliotecarios - y su papel en el equipo multidisciplinario de la UAB aún se discute poco en el marco de los participantes de la Educación Superior de las Instituciones Públicas. Esta investigación aborda el tema de bibliotecario en el contexto del polo de apoyo a la clase de la UAB. Su objetivo general es investigar si existen bibliotecas, que brindan acceso a los servicios de información que se 


\section{Revista Docência e Cibercultura}

ofrecen a los estudiantes de Polos de la UAB, y si hay bibliotecario en los polos actuando de acuerdo con la propuesta de UAB y Quality Benchmarks System for Higher Education and Distance the instruments de evaluación del Ministerio de Educación, y objetivos específicos para identificar qué servicios de acceso a la información ofrecen las bibliotecas, estudiantes de la UAB y conocer el papel de la bibliotecaria en los polos de apoyo a la clase de la UAB. Inicialmente fue necesario aumentar el conocimiento de la Educación a distancia, la UAB y la legislación pertinente a esta modalidad educativa en Brasil, para comprender mejor y alcanzar los objetivos de la investigación, contando con el apoyo ad hoc de los polos de la UAB. Recopilar datos de las bibliotecas de los Centros para el Apoyo en el Aula a partir de la información provista por los coordinadores de los centros que fueron seleccionados al azar. Para recopilar datos, optamos por el cuestionario, disponible en línea y se considera apropiado para esta investigación. Los datos fueron analizados e interpretados considerando los objetivos de las bibliotecas de polos de apoyo a la clase de la UAB seleccionados al azar. Los resultados apuntan a la conclusión de que las bibliotecas de Poles Support Face the UAB, aún no se han adaptado al modelo ODL establecido actualmente en el país para la distancia de educación superior y, por lo tanto, no satisfacen las necesidades de los estudiantes. Los resultados muestran que es necesario establecer políticas públicas a nivel estatal y municipal para garantizar la implementación, el mantenimiento y el funcionamiento de las bibliotecas de acuerdo con la legislación vigente. Este estudio propone sugerencias de mejoras para adaptarse a las bibliotecas de los polos a las demandas de los estudiantes de los cursos ofrecidos por IPES.

Palabras clave: bibliotecario; Universidad Abierta de Brasil; Aula de apoyo de los polacos; Biblioteca. La educación a distancia.

\section{Introdução}

A crescente demanda por educação superior no mundo e também no país, torna-se um desafio para os sistemas educacionais com integralidade. Para atender uma demanda cada vez mais crescente por acesso à educação superior, as IES públicas e privadas têm adotado a modalidade da $\mathrm{EaD}$ estimulando e dando oportunidades da formação superior a um público que encontra-se distanciado dos grandes centros. Litto (2009), Moore e Kearsley (2007) e Anohina (2005) ressaltam que essa nova forma de expandir o ensino superior viabiliza um ensinoaprendizagem diferenciado metodologicamente dos cursos presenciais e consequentemente uma educação de qualidade com um padrão igual ao ensino presencial, no tocante ao quadro de docentes e uma estrutura de biblioteca.

Com o crescimento da EaD no ensino superior, surge um desafio para as bibliotecas universitárias, no sentido de se adequarem ao atendimento de qualidade e as necessidades dos usuários dessa modalidade de ensino, que é diferenciada do atendimento ao aluno presencial.

No Brasil, a EaD tem uma função de responsabilidade social e vem trabalhado para levar uma educação de qualidade à sociedade. A gestão das informações produzidas nos sistemas 


\section{Revista Docência e Cibercultura}

educacionais precisa ser sistematizada possibilitando o acesso eficiente. Essa organização necessita de profissionais capacitados, e aqui se enquadra o bibliotecário, para trabalharem eficientemente com a informação para atender às necessidades de estudantes, tutores e professores.

As bibliotecas (físicas, digitais e virtuais) fazem parte do contexto organizacional e pedagógico das instituições de ensino superior (IES), participando de forma direta nos processos de ensino-aprendizagem e sendo apresentadas, pelo MEC como itens indispensáveis para disponibilizar bibliografias básica e complementar constante do Projeto Pedagógico do Curso (PPC) e também nos Planos de Desenvolvimento Institucional (PDI) das IES nos processos de credenciamento, avaliação e (re)credenciamento de cursos quer seja presenciais ou a distância.

Este artigo apresenta a situação dos polos de $\mathrm{EaD}$, quanto ao quesito obrigatório de fornecer uma biblioteca capaz de prover aos seus estudantes a informação, juntamente com os novos papeis do profissional da informação. $O$ artigo responde o questionamento se as bibliotecas, bibliotecários e serviços de acesso à informação nos polos da UAB estão em conformidade com os RQESD e com os Instrumentos de Avaliação do MEC para Bibliotecas.

O estudo partiu da hipótese da inexistência de bibliotecários e oferta de serviços, em desacordo com RQESD, nos polos da UAB. Teve como objetivo investigar a forma de ofertas de serviços informacionais aos estudantes dos polos da UAB, se existem bibliotecários nos polos atuando em conformidade com a proposta da UAB e como os serviços de acesso às informações são oferecidos pelas bibliotecas aos estudantes da $\mathrm{EaD}$. Para atender a esse objetivo foram trabalhados os objetivos específicos: analisar o funcionamento das bibliotecas dos polos da UAB conforme os parâmetros legais; Identificar atuação dos bibliotecários nos polos e propor sugestões de melhorias no sentido de adequá-las aos critérios levantados.

O foco do estudo foi investigar e mostrar a situação dos polos da UAB quanto às políticas institucionais, as instalações e os padrões de disponibilização de recursos informacionais aos estudantes da $\mathrm{EaD}$, analisando o quesito biblioteca como suporte pedagógico indispensável juntamente com as metodologias de ensino-aprendizagem.

\section{A Biblioteca no Contexto da Educação a Distância}

As bibliotecas dos polos de $\mathrm{EaD}$ fazem parte deste contexto de expansão desta modalidade, de acordo com o Decreto $n^{\circ}$ 5.622/2005 (BRASIL, 2005) os cursos a distância 


\section{Revista Docência e Cibercultura}

devem ter em sua infraestrutura de apoio bibliotecas nos polos com acervo amplo, atualizado e compatível com as disciplinas dos cursos ofertados em diferentes suportes midiáticos.

A biblioteca é um item obrigatório nos PDI das IES de acordo com a Lei de Diretrizes e Bases da Educação Nacional (LDBN) n. o 9394/96, (BRASIL, 1996) em todos os níveis e modalidades do ensino. As bibliotecas sejam tradicionais, digitais ou virtuais são exigidas para o andamento e desenvolvimento dos estudos, para a aquisição do conhecimento e cultura por parte dos estudantes e professores.

A biblioteca faz parte do contexto organizacional e pedagógico das IES, participando de forma direta nos processos de ensino-aprendizagem, promovendo benefícios significativos à educação de forma colaborativa, ao desenvolvimento da autonomia do estudante da $\mathrm{EaD}$. $\mathrm{O}$ papel da biblioteca é dar suporte e complementação aos processos de ensino-aprendizagem disponibilizando a bibliografia indicada e complementar das disciplinas dos cursos oferecidos pela IES.

As bibliotecas têm a função primordial de apoiar as pesquisas e promover o acesso à informação e o bibliotecário por ser o profissional responsável para intermediar o acesso à informação, permitindo aqueles que a procuram possam usufruir desse acesso.

$\mathrm{O}$ art. 12 do Decreto $\mathrm{n}^{\circ}$ 5.622/2005 trata do credenciamento de IES para oferta da EaD e para isso é necessário o cumprimento de alguns requisitos, entre eles os incisos VII e X 'a' e 'd' (BRASIL, 2005a)

[...] VII - garantia de corpo técnico e administrativo qualificado;

$\mathrm{X}$ - descrição detalhada dos serviços de suporte e infra-estrutura adequados à realização do projeto pedagógico, relativamente a:

[...] d) bibliotecas adequadas, inclusive com acervo eletrônico remoto e acesso por meio de redes de comunicação e sistemas de informação, com regime de funcionamento e atendimento adequados aos estudantes de educação a distância.

Referente ao inciso $X$ ' $a$ ' infraestrutura de sistemas tecnológicos de comunicação, a presença de laboratórios didáticos equipados, no caso de projetos de cursos que precisam de atividades em laboratórios, biblioteca e salas de estudo tornarão possíveis a interação entre os estudantes, professores e tutores.

Em relação ao item biblioteca presente no inciso $X$ ' $d$ ' as IES que ofertam a modalidade EaD precisam cumprir esse quesito da legislação para assegurar aos estudantes, professores e tutores 


\section{Revista Docência e Cibercultura}

o acesso às mais variadas formas, meios e fontes por onde circula a informação para se desenvolver nos seus usuários habilidade e competências para transformar a informação em novos conhecimentos.

Nos RQESD (BRASIL, 2007c), documento publicado pelas extinta Secretaria de Educação a Distância (SEED) do MEC, que são adicionados aos atos legais vigentes, servem como referência para as comissões de avaliação dos cursos na EaD.

Neste documento, o polo passa a integrar, com especial ênfase, o conjunto de instalações que receberá avaliação externa, quando do credenciamento institucional para a modalidade da $\mathrm{EaD}$.

De acordo com os RQESD, não existe um único modelo de EaD e as IES ficam livres para criar e definir os modelos dos cursos a distância ofertados por elas. Os PPC na modalidade da $\mathrm{EaD}$ absorvem categorias que envolvem aspectos pedagógicos, recursos humanos e infraestrutura (BRASIL, 2007c). Devem constar no PPC de um curso da EaD os seguintes itens, além de outros: (v) Equipe multidisciplinar; (vi) Infraestrutura de apoio.

No documento, o item (v) Equipe multidisciplinar da EaD (BRASIL, 2007c), envolve profissionais da gestão acadêmica até o desenvolvimento do processo de ensino-aprendizagem por meio da atuação de vários profissionais, dentre eles o bibliotecário.

No quadro de profissionais técnicos-administrativo que atuam na área, tecnológica e administrativa, dando suporte especializado em diferentes setores se insere-se o bibliotecário. Este profissional tem como função oferecer o apoio necessário para realização, em toda sua plenitude, dos cursos ofertados atuando em conjunto com a equipe responsável pela gestão do curso e nos polos de EaD.

O Item (vi) do RQESD, se refere a infraestrutura de apoio a $\mathrm{EaD}$, e determina que além dos recursos humanos e educacionais, a EaD proporciona uma infraestrutura física e material capaz de proporcionar o desenvolvimento das práticas acadêmicas concebidas no PPC (BRASIL, 2007c).

O polo de EaD tem a função de apoio pedagógico e administrativo aos estudantes da $\mathrm{EaD}$, oportunizando o encontro presencial de estudantes, tutores e professores. Nos polos, os estudantes poderão realizar trabalhos em grupo, bem como os meios necessários para discussão e interação com o ambiente virtual de aprendizagem (AVA), além da avaliação presencial. De acordo com a Portaria Normativa $\mathrm{n}^{0}$ 2/2007, o polo "é a unidade operacional para 


\section{Revista Docência e Cibercultura}

desenvolvimento descentralizado de atividades pedagógicas e administrativas relativas aos cursos e programas ofertados a distância” (BRASIL, 2007b).

Os RQESD trazem orientações às IES que ofertam curso em EaD quanto ao planejamento dos seus programas, reforçando em seu conteúdo, a importância da existência de infraestrutura de apoio nos polos, nela incluída, obrigatoriamente, a existência da biblioteca.

$\mathrm{O}$ documento mostra a existência da biblioteca no polo de $\mathrm{EaD}$, com espaços dimensionados para estudo individual e em grupo; acervo atualizado, amplo e compatível com as disciplinas dos cursos e disponibilizados em diferentes mídias. Nesse entendimento, a informatização das bibliotecas oportuniza o acesso dos serviços oferecidos por ela e guiado pelo bibliotecário a toda comunidade da $\mathrm{EaD}$.

Os estudantes da $\mathrm{EaD}$ têm um perfil diferenciado, com características próprias de aluno autodidata, autônomo, administrador do seu tempo. Para isso, segundo Abdelrahman (2012, p. 19 tradução nossa) “[...] os estudantes a distância devem ter acesso a informação e aos serviços de biblioteca com apoio adequado, por esses estarem longe da biblioteca sede da IES". Necessitam e precisam ser orientados pelos bibliotecários para ajudá-los a localizar e utilizar os recursos e serviços disponíveis no AVA na busca da informação para desenvolvimento de qualidade dos suas pesquisas. Os avanços das Tecnologias da Informação e Comunicação (TIC) e as bibliotecas digitais/virtuais têm contribuído positivamente para cobrir a lacuna de informação para estudantes da EaD.

A biblioteca e os profissionais da informação precisam estar preparados para atender às necessidades dos usuários da $\mathrm{EaD}$ que têm um perfil diferenciado. Segundo Cervera (2010), gerenciar os recursos didáticos remotos, isto é em ambientes longe da sala de aula não é tão simples, dessa forma, o autor mostra a importância e necessidade do trabalho conjunto entre docentes e a biblioteca, de forma a garantir que os recursos sejam utilizados covenientemente por todos, onde esses passem de uma posição estática para uma posição dinâmica nos AVA.

Cervera (2010) destaca que a biblioteca pode e deve oferecer acesso de diversos locais e precisa também estar presente nas salas de aula dos Polos. Entretanto o autor adverte que para a efetivação desse processo é necessário à presença do bibliotecário, profissional da informação que deve ter estreita colaboração com o corpo docente da IES e do polo de EaD para atender as diferentes necessidades dos usuários, de acordo com as especificidades de cada programa de ensino superior na EaD. 


\section{Revista Docência e Cibercultura}

\section{O Bibliotecário no Contexto da EaD}

Valentim (2004), afirma que o modelo de equipe multidisciplinar da EaD apresentado nos RQESD, deve se adequar em relação a competência e habilidades que os profissionais recebem durante a formação profissional, ou seja, esse modelo de equipe multidisciplinar é flexível às mudanças sociais, demandando mudanças e adequações curriculares. Sugere a presença de um profissional formado em Ciência da Informação, biblioteconomia, fazendo parte do eixo gerencial e informacional da equipe multidisciplinar da $\mathrm{EaD}$.

Mesmo quando a IES disponha de uma infraestrutura adequada e de um corpo docente qualificado, é necessário que o bibliotecário se faça presente atuando como disseminador da informação e esteja disponível para orientação à pesquisa. Entretanto para Souto (2010, p. 12):

Não é comum ao se desenvolver um projeto de EaD levar em consideração as formas de orientação aos estudantes, quanto à obtenção de material complementar. Por melhor que sejam os recursos didáticos oferecidos pelo programa, em determinadas situações, haverá necessidade de se consultar outras fontes para aprofundamento no assunto ou simplesmente para se esclarecer algumas dúvidas que venham a aparecer durante o processo de aprendizagem.

É oportuno pensar em ter o bibliotecário na equipe multidisciplinar da EaD. A integração deste será útil não só porque domina as técnicas, mas também porque é o profissional que vai atender às necessidades dos usuários que buscam pela informação. O bibliotecário na equipe multidisciplinar da EaD está habilitado a participar da modalidade, tendo em vista as TIC atuando ativamente na sociedade atual, armazenando e circulando informações para a formação das competências do futuro.

O bibliotecário dispõe de conhecimentos específicos em fontes de informação podendo orientar não só estudantes, mas contribuir com toda a equipe envolvida que atua no gerenciamento e desenvolvimento da EaD. Atua como como um mediador de conhecimentos mantendo-se atualizado sobre a bibliografia e fontes de informação, instrumentos do conhecimento, dos cursos, para manter os padrões de qualidade dos cursos e promover o diferencial na equipe interdisciplinar dessa modalidade de ensino-aprendizagem. 


\section{Revista Docência e Cibercultura}

As competências do bibliotecário para trabalhar em projetos de $\mathrm{EaD}$, devem envolver habilidades técnicas, sociais e educacionais mínimas para assumir o papel de agente educativo nos AVA. Segundo Blattmann e Belli (2000, p. 7), os serviços disponibilizados pela biblioteca na EaD utilizando as TIC caracterizam uma nova concepção. "A biblioteca deixa de ser um tranquilo depósito de livros para tornar-se o ponto focal de pesquisa variada, acessada a qualquer hora por usuários virtuais de vários lugares do mundo." Para Levacov $(1997$, p. 1) "trata-se de uma visão das possibilidades de acesso à informação, decorrentes do surgimento das chamadas bibliotecas sem paredes". O novo modelo de biblioteca é que deve estar presente na $\mathrm{EaD}$ com bibliotecários preparados e atuantes.

Os estudantes da EaD tornaram-se mais independentes, o que exige uma atuação mais efetiva do bibliotecário para atender um público familiarizado com tecnologias e conectado a redes virtuais. Os bibliotecários se preocupam em orientar na busca e recuperação da informação, função importante para os estudantes da EaD, considerando ser essa modalidade mediada com o uso das TIC.

Blattmann e Dutra (1999), Mueller (2000), Blattmann (2001), Noah e Braun (2002), afirmam que as atividades dos bibliotecários nos sistemas de $\mathrm{EaD}$, podem se categorizar em quatro atividades principais, com atuação:

a) na organização das bibliotecas da instituição educacional para atendimento aos estudantes da $\mathrm{EaD}$, tanto nas bibliotecas digitais/virtuais como nas tradicionais;

b) na atuação nos polos de $\mathrm{EaD}$ na organização da biblioteca e em serviços associados (BRASIL/MEC/UAB, 2008);

c) nas equipes multidisciplinares que atuam na produção de materiais didáticos, tratamento e padronização das atividades de $\mathrm{EaD}$, essencialmente organizando o acervo dos recursos educacionais nos AVA e impressos gerados nas instituições para busca, catalogação, indexação, armazenamento e padronização nas bibliotecas, repositórios e em ambientes virtuais de ensino-aprendizagem; d) na organização dos recursos educacionais abertos (REA).

Cruz (2007, p. 13), enfatiza que os bibliotecários na EaD, estão aptos para atuarem como colaboradores no processo ensino-aprendizagem, atendendo as necessidades informacionais 


\section{Revista Docência e Cibercultura}

dos estudantes, entendendo que acesso a informação é fator primordial para o bom desempenho dos cursos na modalidade a distância.

\section{A Biblioteca no Contexto da UAB}

Com base nos art. 80 e 81 da LDBN Lei n $9.394 / 96$ e no Plano Nacional de Educação (PNE), o Sistema UAB foi criado pelo Decreto Presidencial de $\mathrm{n}^{\circ}$. 5.800/2006(b), tendo como características,

[...] articulação e integração de um sistema nacional de educação superior à distância, em caráter experimental, visando sistematizar as ações, programas, projetos, atividades pertencentes às políticas públicas voltadas para a ampliação e interiorização da oferta do ensino superior gratuito e de qualidade no Brasil (BRASIL, 2006b).

Esse Decreto criou o Sistema UAB, tendo o MEC, inicialmente através da SEED e depois pela CAPES, a função de coordenar a articulação entre as IPES já existentes para levar ensino superior de qualidade aos municípios brasileiros que não têm oferta, ou cujos cursos ofertados não são suficientes para atender à demanda existente.

A UAB é o sistema integrado por IPES com o objetivo de oferecer cursos superiores na modalidade a distância para população que têm dificuldades de acesso à formação de nível superior. Tem como prioridade a formação inicial a professores da educação básica oferecendo cursos de graduação e também formação continuada àqueles já graduados, além de ampliar a oferta de cursos a dirigentes, gestores e outros profissionais da educação básica da rede pública. Dessa forma tenta reduzir as desigualdades socioculturais no país e para atender a esses objetivos, foram criados polos de $\mathrm{EaD}$ com adequada infraestrutura, tendo como objetivo o desenvolvimento dos estudantes em conjunto com tutores e professores das atividades pedagógicas.

A UAB foi instituída pelo Decreto $\mathrm{n}^{\mathrm{o}} 5.800$, de 8 de junho de 2006, para "o desenvolvimento da modalidade de $\mathrm{EaD}$, com a finalidade de expandir e interiorizar a oferta de cursos e programas de educação superior no país" (BRASIL, 2006b) e atua como articulador entre as IPES e as três esferas governamentais federal, estadual e municipal, com vistas a atender às demandas locais em educação superior. Segundo a UAB (2013) essa articulação 


\section{Revista Docência e Cibercultura}

estabelece qual IPES deve ser responsável por ministrar determinado curso em determinado município ou certa microrregião por meio dos polos de EaD.

Efetuada a articulação entre as IPES e os Polos de EaD, o Sistema UAB assegura o fomento de ações, que visam a assegurar o bom funcionamento dos cursos. A Diretoria de EaD (DED) da Capes apoia a atuação das IPES na oferta de cursos no âmbito da UAB para: produção e distribuição do material didático impresso utilizado nos cursos; aquisição de livros para compor as bibliotecas; utilização de TIC para interação entre os docentes, tutores e estudantes; aquisição de laboratórios pedagógicos; infraestrutura dos núcleos de EaD nas IPES participantes; capacitação dos profissionais envolvidos; acompanhamento dos polos de apoio presencial; e encontros presenciais para o desenvolvimento da $\mathrm{EaD}$.

No Decreto $\mathrm{n}^{\mathrm{o}} 5.800 / 2006$, o Poder Público disciplinou as linhas gerais a UAB, destacando o espaço do polo de $\mathrm{EaD}$, definido como "[...] unidade operacional para o desenvolvimento descentralizado de atividades pedagógicas e administrativas relativas aos cursos e programas ofertados a distância pelas IPES”. O polo de EaD se constitui no elemento mais característico do Sistema UAB e é parte fundamental na articulação de todo sistema (BRASIL, 2006b).

Os polos de $\mathrm{EaD}$ devem dispor de biblioteca, laboratório de informática, tutoria presencial, espaço para aulas presenciais e práticas de laboratório. Para seu funcionamento os polos devem ter uma equipe multidisciplinar para o desenvolvimento das atividades administrativas e acadêmicas composta de coordenador de polo, secretária, profissional de biblioteca, tutores, técnico de Informática, técnicos de laboratórios pedagógicos, técnicos de apoio e pessoal de limpeza e conservação.

É no polo de EaD que se promove as condições necessárias para a permanência do estudante no curso e neles se deve sistematizar vínculo com a IPES que ofertam os cursos, podendo, estimular e constituir fator de integração e desenvolvimento sócio-econômico e cultural da região.

O credenciamento de polo de EaD envolve a solicitação para implantação de novos polos da UAB e é feita através de Fóruns Estaduais Permanentes de Apoio à Formação Docente $^{5}$, com o aval do mantenedor do polo (BRASIL, 2009b).

\footnotetext{
${ }^{5}$ Órgãos colegiados criados para dar cumprimento aos objetivos da Política Nacional de Formação de Profissionais do Magistério da Educação Básica. Entre as principais funções do Fórum, estão: elaborar e acompanhar a execução de um plano estratégico; definir prioridades e metas do programa em cada estado; coordenar as ações de formação de professores; e propor ações específicas para garantia de permanência e rendimento satisfatório dos professores
} 


\section{Revista Docência e Cibercultura}

Compete à Capes analisar as solicitações para implantação de novos polos da UAB, além de providenciar análises geopolíticas acerca da implantação dos mesmos nos municípios solicitantes, respaldado pela Portaria Capes no 75, de 14 de abril de 2010 (BRASIL, 2010).

De acordo com a Capes (BRASIL, 2010), o polo de EaD deverá ter a seguinte infraestrutura física, tecnológica e de recursos humanos: a edificação deve ser compatível com os propósitos do polo, com espaços físicos adequados, acesso fácil, banheiros femininos e masculinos, rede elétrica adequada para suporte dos equipamentos técnicos, acessibilidade; sala com espaço físico adequado, para a Coordenação de Polo com computador conectado a internet; sala com espaço físico adequado para a Secretaria Acadêmica com computador conectado à internet; salas com espaço físico compatível e adequado às atividades essenciais para atendimento e acompanhamento aos estudantes; salas com mobiliário adequado; espaço físico adequado às atividades de tutoria com computadores completos e conectados a internet; espaço físico para a biblioteca com mobiliário adequado e espaço para estudos individuais e em grupo; acervo bibliográfico básico e complementar para os cursos ofertados; laboratório de Informática com no mínimo 25 computadores completos com acesso a internet para atendimento aos estudantes dos cursos; placa de identificação conforme manual visual da Capes.

A biblioteca do polo deve possuir como mobiliário: mesas para quatro pessoas, cadeiras estofadas, cadeiras giratórias, mesa para computador, mesa de escritório, armários com fechaduras, mesa para impressora, armário com 2 portas e estantes de aço. Além do mobiliário, precisa oferecer os equipamentos de projetor multimídia e webcam (CAPES, 2013).

Quanto aos recursos tecnológicos, a Capes recomenda que o polo tenha rede de internet com número de pontos de acesso compatíveis com as atividades acadêmicas do polo de EaD.

O processo de avaliação dos Polos de EaD das IES interessadas em ofertar cursos a distância é realizado in loco pelo MEC para o credenciamento ou recredenciamento da instituição, autorização e reconhecimento de cursos de acordo com a Portaria Normativa $n^{\circ} 2$, de janeiro de 2007, (BRASIL, 2007b) que dispõe dos procedimentos de regulação e avaliação da educação superior na EaD.

de educação básica. Tem a finalidade organizar a formação inicial e continuada dos profissionais do magistério para as redes públicas da educação básica, em regime de colaboração entre a União, os Estados, o Distrito Federal e os Municípios, a formação inicial e continuada dos profissionais do magistério para as redes públicas da educação básica. 


\section{Revista Docência e Cibercultura}

Para o credenciamento do polo de $\mathrm{EaD}$, em relação a infraestrutura para funcionamento do mesmo, uma das principais exigências é dispor bibliotecas físicas e virtuais, garantindo aos estudantes, tutores e professores o acesso as informações e os conteúdos do curso.

A biblioteca disponibiliza serviços e recursos bibliográficos, em meio físico, digital e virtual, proveniente de fontes confiáveis, com o objetivo de oferecer suporte informacional aos usuários da EaD. Deve ter todas as condições para atender o polo da $\mathrm{UAB}$, que vai desde a estrutura física até recursos humanos especializados e aqui entra o bibliotecário e os auxiliares de bibliotecas para o atendimento aos estudantes para orientar gestores e mantenedores das IPES.

\section{A biblioteca no contexto do Polo da UAB}

Em conformidade com o Edital de Seleção nº. 01/2005-SEED/MEC (BRASIL, 2005), é de incumbência dos municípios selecionados para a oferta dos cursos da UAB, comprovarem capacidade técnica e financeira para instalar e manter as estruturas necessárias para o atendimento dos Polos. Segundo o edital de seleção de polos da UAB, no item 3 alínea c "biblioteca, contendo pelo menos o acervo bibliográfico mínimo, inclusive biblioteca virtual, para o curso que se pretende ofertar" (BRASIL, 2005a). A biblioteca digital/virtual aparece no contexto da UAB como o modelo adotado para possibilitar o acesso às informações aos estudantes.

Se faz necessário avaliar as reais condições das bibliotecas dos polos da UAB, para confrontar com as exigências constantes do referido edital.

Segundo Garcez (2002) e Marchiori (1997), a biblioteca virtual surge no contexto da EaD como uma alternativa viável ao acesso às informações e serviços em tempo real aos estudantes. Entretanto, o aparato operacional requer investimentos em recursos tecnológicos, acervo e recursos humanos qualificados.

A existência das bibliotecas virtuais nos polos da UAB, ainda é um tanto complexa, mesmo com o apoio das TIC, pois na atual situação faltam planejamento e diretrizes eficazes para uma consolidação de ações em gestão das bibliotecas nos polos, se for observado alguns requisitos, considerados nos RQESD, como fundamentais para o funcionamento dos polos de $\mathrm{EaD}$, em relação às bibliotecas.

O funcionamento do Sistema UAB é caracterizado pela forma de parceria com as IPES, cabe a estas, ter um planejamento eficiente para as bibliotecas dos polos de $\mathrm{EaD}$, definindo diretrizes de acordo com suas competências e atribuições, além de proporcionar meios para 


\section{Revista Docência e Cibercultura}

auxiliá-las nos processos relacionados à gestão técnica e administrativa, em relação às atividades e serviços a que se propõem enquanto órgão de apoio ao ensino-aprendizagem.

Nos RQESD (BRASIL, 2007c), são definidas orientações gerais às IES, sobre a necessidade de existência de biblioteca nos polos de EaD. Este documento reforça a necessidade de existência de acervo mínimo para possibilitar acesso aos estudantes à bibliografia indicada nos cursos, além da oferta de serviços de empréstimo de materiais, acesso a periódicos e a outros recursos ligados à biblioteca central da IES para possibilitar acesso à bibliografia completar, necessária durante o curso.

Nesse entendimento, a disponibilidade de serviços de acesso às informações, a existência de acervo bibliográfico e de instalações físicas adequadas, formam um tripé importante no contexto da necessidade de existência de bibliotecas estruturadas nos polos da $\mathrm{UAB}$.

Além das diretrizes estabelecidas nos RQESD para a EaD, o MEC criou instrumentos de avaliação, para os cursos a distância, nos quais são avaliadas algumas dimensões em relação à instituição, aos polos de $\mathrm{EaD}$ e às condições de oferta dos cursos e uma delas se refere à infraestrutura, inserindo questões relacionadas à biblioteca.

No quadro 1, estão pontuados na regulação do ensino superior a distância no país os itens relacionados com as bibliotecas dos polos de $\mathrm{EaD}$ em conformidade aos vários instrumentos avaliativos do MEC. As bibliotecas são sempre um ponto focal de avaliação, independente do tipo de modalidade de ensino ofertada. A existência de bibliotecas nas IES requer infraestrutura condizente aos objetivos educacionais, seja de instalações físicas, mobiliário adequado, acervo compatível com as necessidades dos cursos e dos usuários. Nesse espaço estão disponibilizadas o material informacional, oferta de serviços e produtos de acesso à informação em meio tradicional ou virtual, mediado pelo bibliotecário.

\section{Quadro 1 - Critérios de avaliação para as bibliotecas dos Polos da UAB}

\begin{tabular}{|l|l|}
\hline Avaliação & Itens de avaliação das bibliotecas (Polos e sede) \\
\hline $\begin{array}{l}\text { Avaliação de } \\
\text { Cursos de Graduação }\end{array}$ & $\begin{array}{l}\text { Condições de atendimento do acervo da bibliografia básica e } \\
\text { complementar, conforme indicadores; existência de periódicos } \\
\text { especializados; utilização da biblioteca virtual. }\end{array}$ \\
\hline
\end{tabular}




\section{Revista Docência e Cibercultura}

\begin{tabular}{|l|l|}
\hline \multirow{2}{*}{ Credenciamento } & $\begin{array}{l}\text { Infraestrutura de pessoal projetada; espaço físico existente } \\
\text { (instalações para acervo, estudo individual e em grupo); } \\
\text { equipamentos disponíveis na biblioteca, livros da bibliografia } \\
\text { básica (conforme quantidade indicada); livros da bibliografia } \\
\text { complementar; assinaturas de periódicos especializados; } \\
\text { existência de Biblioteca Virtual. }\end{array}$ \\
\hline Institucional & $\begin{array}{l}\text { Existência de corpo administrativo para atuar na gestão das } \\
\text { bibliotecas dos polos; instalações para o gerenciamento central } \\
\text { das bibliotecas dos polos e para manipulação do acervo; } \\
\text { informatização do sistema de bibliotecas que administra a } \\
\text { biblioteca dos polos; política de expansão, aquisição e } \\
\text { atualização do acervo dos polos. }\end{array}$ \\
\hline Autorização de cursos & $\begin{array}{l}\text { Existência de livros da bibliografia básica e complementar na } \\
\text { sede da instituição; existência de assinaturas de periódicos } \\
\text { especializados (impressos ou informatizados); existência de } \\
\text { bibliografia básica na proporção indicada no polo; existência de } \\
\text { bibliografia complementar no polo. }\end{array}$ \\
\hline $\begin{array}{l}\text { Existência de instalações para acervo, e funcionamento da } \\
\text { biblioteca considerando (dimensão, limpeza, iluminação, } \\
\text { acústica, ventilação, segurança, conservação e comodidade); } \\
\text { instalações para estudo em grupo e individual; existência de } \\
\text { livros da bibliografia básica na proporção indicada; existência de } \\
\text { bibliografia complementar; existência de assinaturas de } \\
\text { periódicos especializados, indexados e correntes (impressos ou } \\
\text { informatizados); existência de biblioteca virtual. }\end{array}$ \\
\hline avalo
\end{tabular}

Fonte: BRASIL (2010).

Considerando a importância do Sistema UAB para o ensino superior público no país, as bibliotecas dos polos são estruturas de apoio e um instrumento que ofertam serviços relevantes, auxiliando os estudantes de todas as formas, seja presencial, virtual ou por telefone, quanto às suas dúvidas informacionais, devendo se constituir em um meio eficaz de divulgação e disseminação das informações. 


\section{Revista Docência e Cibercultura}

De acordo com os RQESD (BRASIL, 2007c, p. 19), "os recursos humanos devem configurar uma equipe multidisciplinar com funções de planejamento, implementação e gestão de cursos à distância" que deve ser composta por três categorias profissionais: docentes, tutores e pessoal técnico-administrativo.

O bibliotecário, na equipe multidisciplinar do polo, insere-se na dimensão administrativa do pessoal técnico-administrativo, "na distribuição e recebimento de material didático, atendimento a estudantes usuários de [...] bibliotecas” (BRASIL, 2007, p. 23).

Segundo Brasil (2002), para o exercício dessas ocupações a Classificação Brasileira de Ocupações (CBO) indica que se deve possuir curso de "[...] bacharelado em Biblioteconomia e Documentação. A formação é complementada com aprendizado tácito no local de trabalho e cursos de extensão". A formação é realmente fator preponderante na vida profissional, pois é ela que propiciará a base de todo o conhecimento para o desenvolvimento das atividades profissionais.

Caberá ao bibliotecário gerenciar a biblioteca dos polos da UAB, utilizar as TIC para planejar, executar, coordenar e avaliar os recursos e serviços da biblioteca que se destina ao público da $\mathrm{EaD}$ e, as IPES, juntamente com as mantenedoras municipais ou estaduais, a responsabilidade equipar os cursos em $\mathrm{EaD}$ equipamentos suficientes, acessibilidade e oferecer recursos humanos - bibliotecários e auxiliares - proporcionando um atendimento eficiente e de qualidade aos estudantes da $\mathrm{EaD}$.

\section{Acesso a Informação nos Polos de EaD do Sistema UAB}

Para este estudo foram selecionados, por sorteio aleatório, 5 (cinco) polos ${ }^{6}$ aptos (AA) ${ }^{7}$ da UAB por estado contemplando 26 estados brasileiros. Para participação na amostra do estudo, os polos não deveriam ser polos associados ${ }^{8}$, justificado pelo fato de estarem inseridos nos campus das IPES nos quais as bibliotecas centrais e dos campus por serem entendidas e contabilizadas como parte do polo.

\footnotetext{
6 Alguns estados não possuem cinco polos (AA).

7 Apto (AA) - Situação que indica a adequação da infraestrutura física, tecnológica e de recursos humanos do Polo, bem como a existência de toda a documentação necessária. O polo está liberado pela DED/Capes para a articulação de cursos que não requeiram instalações específicas e para cursos que precisem de instalações e equipamentos pedagógicos, caso o polo disponha de tais instalações e equipamentos. Disponível em: <http://uab.capes.gov.br/index.php/polos-841 937/avaliacao-de-polos>.

8 Polo associado é aquele mantido pela IPES.
} 


\section{Revista Docência e Cibercultura}

Este estudo teve como objetivo identificar e explicar a realidade das biblioteca nos polos da UAB e conhecer, analisar e avaliar a situação das bibliotecas dos polos e verificar se estas atendem às demandas dos estudantes dos cursos ofertados a distância pela UAB.

Os dados coletados junto às bibliotecas das amostras dos polos selecionados foram analisados e interpretados buscando conhecer a realidade, levando-se em consideração os RQESD, os instrumentos de avaliação dos cursos de graduação e a condução das IPES envolvidas no processo do Sistema $\mathrm{UAB}$, em relação às três esferas nacional, estadual e municipal.

Foi construído um questionário online para coleta de dados, aplicado aos coordenadores dos polos da UAB sorteados aleatoriamente para esta pesquisa, conservando na totalidade o sigilo os dados pessoais dos respondentes. O retorno dos dados fornecidos a partir desse instrumento de pesquisa permitiu a construção de gráficos dando feedback para uma visualização estatística em relação ao item biblioteca como suporte a EaD a nível nacional e em específico a presença de bibliotecas nos polos da UAB pesquisados.

Para esta pesquisa foram escolhidos 127 polos. Desse total, 43 responderam ao questionário, no período de 15/03 a 30/08/2015 Esses 43 respondentes se tornaram, nessa pesquisa, os 100\% da população estudada.

O universo escolhido da pesquisa foram os coordenadores dos polos da UAB sorteados aleatoriamente, sendo 5 polos em cada um dos 26 estados brasileiros, totalizando 127 polos. Destes, 43 coordenadores de polos responderam ao convite da pesquisa e constituíram a amostra pelos municípios de Cruzeiro do Sul (AC), Taraucá (AC), Maragogi (AL), Matriz de Camaragibe (AL), Olho D’Água das Flores (AL), Santana do Ipanema (AL), São José da Lage (AL), Corarí-União (AM), Lábrea (AM), Conceição do Coité (BA), Rio Real (BA), Beberibe (CE), Campos Sales-Alto Alegre (CE), Caucaia-Novo Pabussu (CE), Meruoca (CE), Afonso Claudio (ES), Domingos Martins (ES), Nova Venécia (ES), São Simão-Popular (GO), CuiabáCentro Sul (MT), Juara (MT), São Gabriel do Oeste-Zona Rural (MS), Alterosa (MG), Bicas (MG), Conceição do Mato Dentro (MG), Marabá (PA), Moju-Liderança (PA), Campina Grande (PB), Pombal (PB), Astorga (PR), Foz do Iguaçu (PR), Gilbués-Santo Antônio (PI), Paes Landim (PI), Regeneração (PI), São Fidelis (RJ), Luís Gomes (RN), Cruz Alta (RS), Ariquemes-Setor Institucional (RO), Laguna-Portinho (SC), Ponte Serrada-Berte (SC), Bragança Paulista-Uberaba (SP), Jaú (SP) e São Paulo-Jardim Esmeralda (SP). 


\section{Revista Docência e Cibercultura}

O questionário foi desmembrado em três dimensões, com base na literatura e focado nos coordenadores de polo da UAB, por serem os representantes legais e estarem aptos a responder sobre o polo no qual atuam, com a garantia do sigilo os dados pessoais dos respondentes. O retorno dos dados fornecidos a partir do questionário permitiu a construção de quadros e gráficos, permitindo a visualização estatística de cada item pesquisado.

O questionário envolveu 14 questões distribuídas nas três dimensões: dados do polo, dados da biblioteca do polo da UAB e dados do bibliotecário do polo (Quadro 2).

\section{Quadro 2 - Estrutura do questionário}

\begin{tabular}{|l|l|l|}
\hline \multicolumn{2}{|l|}{ Estrutura do Questionário Enviado aos Coordenadores dos Polos da UAB } \\
Selecionados por amostragem & Dados do Polo da UAB & $\begin{array}{l}\text { Identifica os polos da UAB em } 26 \text { estados } \\
\text { brasileiros }\end{array}$ \\
\hline $\mathbf{2}$ & Dados da biblioteca do Polo & $\begin{array}{l}\text { Investiga a existência de biblioteca nos polos } \\
\text { selecionados, para esta pesquisa, da UAB de } \\
26 \text { estados brasileiros. }\end{array}$ \\
\hline 3 & Dados do bibliotecário do Polo & $\begin{array}{l}\text { Investiga se existe o bibliotecário nos polos } \\
\text { selecionados da UAB dos 26 estados } \\
\text { brasileiros }\end{array}$ \\
\hline
\end{tabular}

Fonte: Autores (2015).

A aplicação da pesquisa, se deu através dos e-mails, disponibilizados na listagem dos polos AA (SISUAB), enviados aos coordenadores dos polos sorteados para explicar a natureza da pesquisa e obter assim o apoio necessário no recebimento das respostas.

As informações obtidas nos questionários foram analisadas mediante a técnica de análise de conteúdo (BARDIN, 2011), para verificação de hipóteses ou questões e o exame do conteúdo subjacente da linguagem em relação ao contexto em foi produzido, isto é, os sentidos. Para a análise dos dados foram definidas categorias (fig. 1), antes e depois do período de coleta, 


\section{Revista Docência e Cibercultura}

pois a elaboração de categorias nos dois momentos auxilia o pesquisador na classificação dos dados. (GOMES, 1998).

A análise da categoria (1) “Identificação dos Polos da UAB” foi dividida em 2 (duas) subcategorias: quantidade de alunos e quantidade de cursos oferecidos pela UAB.

Figura 1 - Categorias: UAB, biblioteca e bibliotecário
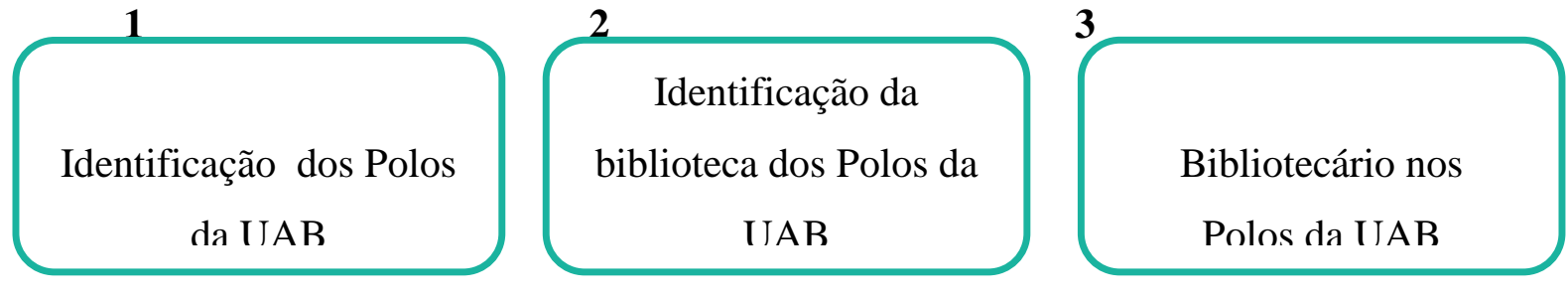

Fonte: Autores (2015)

Para esta categoria foram coletados dados de identificação tais como: localidade, nome do polo, ano da criação dos cursos no polo, quantidade de cursos existentes e a quantidade de estudantes nos polos da UAB.

Nas respostas dos 43 respondentes, o número de cursos é de 332 e o número de estudantes é de 14.745, nota-se que existe uma quantidade significativa de estudantes e um adequado número de cursos para atender a demanda.

Na quantidade dos coordenadores, por região nos estados brasileiros selecionados, que responderam ao questionário, constatou-se que dos 43 polos da UAB investigados na pesquisa, a região Nordeste foi a que mais se destacou em quantidade de participantes (16), seguido da Região Sudeste (10), Norte (8), Sul (5) e Centro Oeste (4).

A categoria (2), "Existência e Características do Polo de EaD”, composto por 5 (cinco) subcategorias, teve como objetivo, identificar os aspectos relacionados à infraestrutura disponível para bibliotecas dos polos, cujos critérios são parte dos itens existentes nos Instrumentos de Avaliação dos Cursos de Graduação instituídos pelo MEC e nos RQESD, quando preveem que não há obrigatoriedade de existência de bibliotecas nos polos, entretanto devem ser oferecidos os recursos de informação e locais adequados para atender as necessidades e demandas informacionais dos estudantes.

Nesta categoria foram analisados: (a) existência de bibliotecas (física e virtual), seu uso e organização; (b) acervo bibliográfico; (c) utilização das bibliotecas pelos estudantes, tutores e professores da $\mathrm{UAB}$; (d) atendimento das bibliotecas às necessidades dos estudantes, tutores 


\section{Revista Docência e Cibercultura}

e professores; (e) comparação da organização das bibliotecas dos polos de $\mathrm{EaD}$ dos cursos $\mathrm{UAB}$ com as bibliotecas dos cursos presenciais das universidades pesquisadas; e (f) estrutura atual do polo e da biblioteca dos polos de EaD dos cursos UAB.

O objetivo foi identificar a existência de bibliotecas em conformidade aos RQESD para o Sistema UAB. De forma similar, a pesquisa procurou conhecer sobre o tipo de acervo e saber da atual estrutura dos polos e, em especial das bibliotecas, se estão devidamente estruturadas para atender aos estudantes, tutores e docentes dos polos da UAB.

O gráfico 1 mostra que em termos de biblioteca física os polos da UAB pesquisados estão adequados, num percentual de $95 \%$ deste importante espaço de acesso a informação.

\section{Gráfico 1 - Biblioteca física nos Polos da UAB}

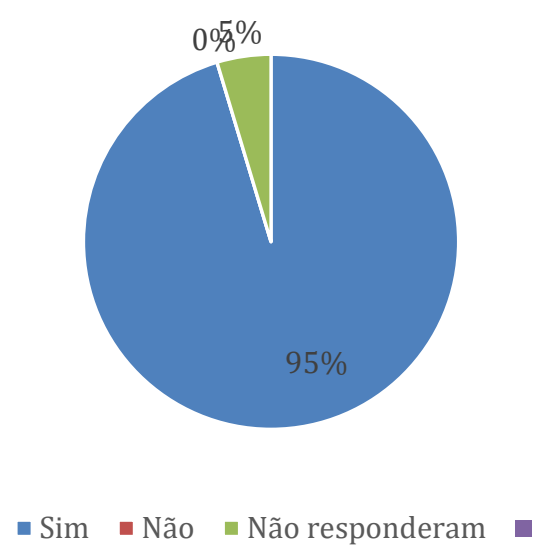

Fonte: Autores (2015).

O gráfico 2 mostra a situação do dos polos em relação a biblioteca virtual por esta ser uma ferramenta de estudo e pesquisa para os cursos em EaD e que vão disponibilizar o acesso a informação. $33 \%$ responderam que tem biblioteca virtual, $65 \%$ não tem e apenas $2 \%$ não responderam a pergunta. $\mathrm{O}$ resultado confirma, portanto, um percentual superior à $50 \%$ da não existência de bibliotecas, funcionando como um canal na localização e recuperação da informação, auxiliando os estudantes, tutores e professores da $\mathrm{EaD}$, em conformidade com os RQESD e com o Sistema UAB.

A apresentação dos dados obtidos na pesquisa permitiu constatar que não existe biblioteca virtual na maioria nos polos da UAB. Analisando os resultados, percebe-se que os estudantes, tutores e docentes da $\mathrm{EaD}$ não têm esse espaço como apoio ao ensinoaprendizagem. 


\section{Gráfico 2 - Biblioteca Virtual nos Polos da UAB}

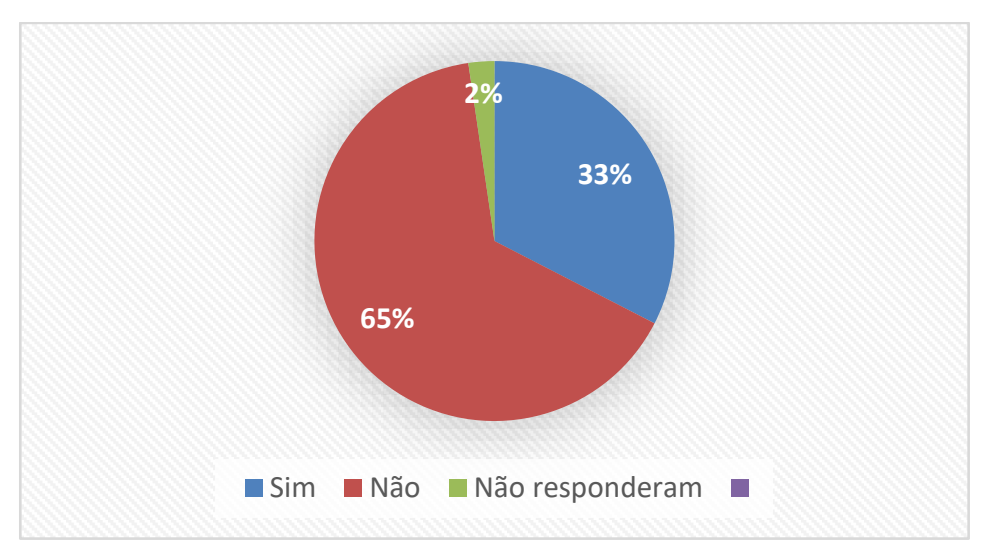

Fonte: Autores (2015).

O Gráfico 3, identifica os tipos de acervo nas bibliotecas dos polos da UAB. De acordo com as resposta dos coordenadores sobre a composição do acervo da biblioteca dos polos pesquisados, em sua maioria, $77 \%$ dispõe obras impressa e eletrônica, $21 \%$ afirmaram ter apenas obras impressas e $2 \%$ não responderam a pergunta.

De acordo com o resultado obtido, os polos estão com acervo satisfatório, o que é positivo na hora da avaliação do MEC, em relação ao item biblioteca para atender às necessidades dos seus cursos.

Os acervos das bibliotecas dos polos da UAB conferem com a EaD, oportunizando o acesso a informação e garantido uma maior qualidade e desenvolvimento de competências a seus usuários.

\section{Gráfico 3 - Tipo de acervo das bibliotecas nos Polos da UAB}

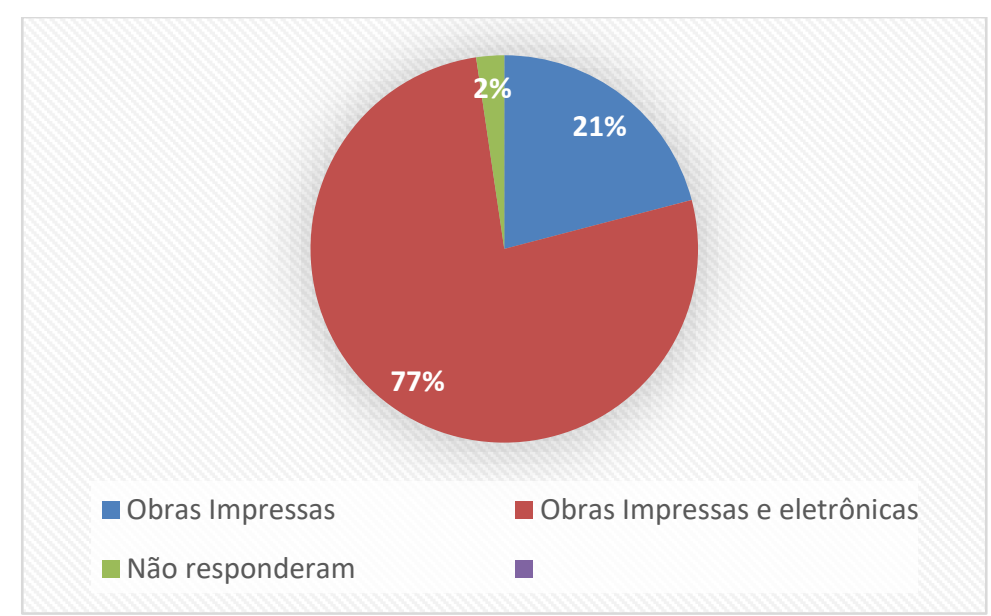

Fonte: Autores (2015). 


\section{Revista Docência e Cibercultura}

$\mathrm{Na}$ atual estrutura do polo e as bibliotecas atendem as necessidades dos estudantes, tutores e docentes dos cursos da UAB. $63 \%$ dos coordenadores responderam que a biblioteca atende totalmente as necessidades dos usuários dos polos da UAB, $21 \%$ afirmaram atender parcialmente, $9 \%$ responderam que não atendem as necessidade dos usuários e $7 \%$ não responderam a essa pergunta (Gráfico 4).

Com base nos resultados obtidos dos 43 coordenadores de polos da UAB, numa percepção de mais de $50 \%$ dos respondentes, a estrutura dos polos da UAB e suas bibliotecas satisfazem ao seu público. Isso evidencia que: a infraestrutura dos polos e das bibliotecas estão de acordo com o Item (vi) dos RQESD, determina que além dos recursos humanos e educacionais, a EaD deve ter uma infraestrutura capaz de proporcionar o desenvolvimento das práticas acadêmicas contemplado no PPC.

Em sua maioria, os polos estão em conformidade aos RQESD, no item biblioteca física, na sua estrutura e no acervo. Aqui os coordenadores deram resposta semelhante sobre o material bibliográfico existente na biblioteca física dos polos da UAB nos quais atuam. Os resultados permitem constatar que os coordenadores conhecem bem o material disponibilizado aos estudantes do polo. Entretanto, fica a desejar no item biblioteca virtual, pois dos 43 coordenadores respondentes apenas 14 informaram ter esse espaço.

\section{Gráfico 4 - Estrutura da biblioteca nos Polos da UAB}

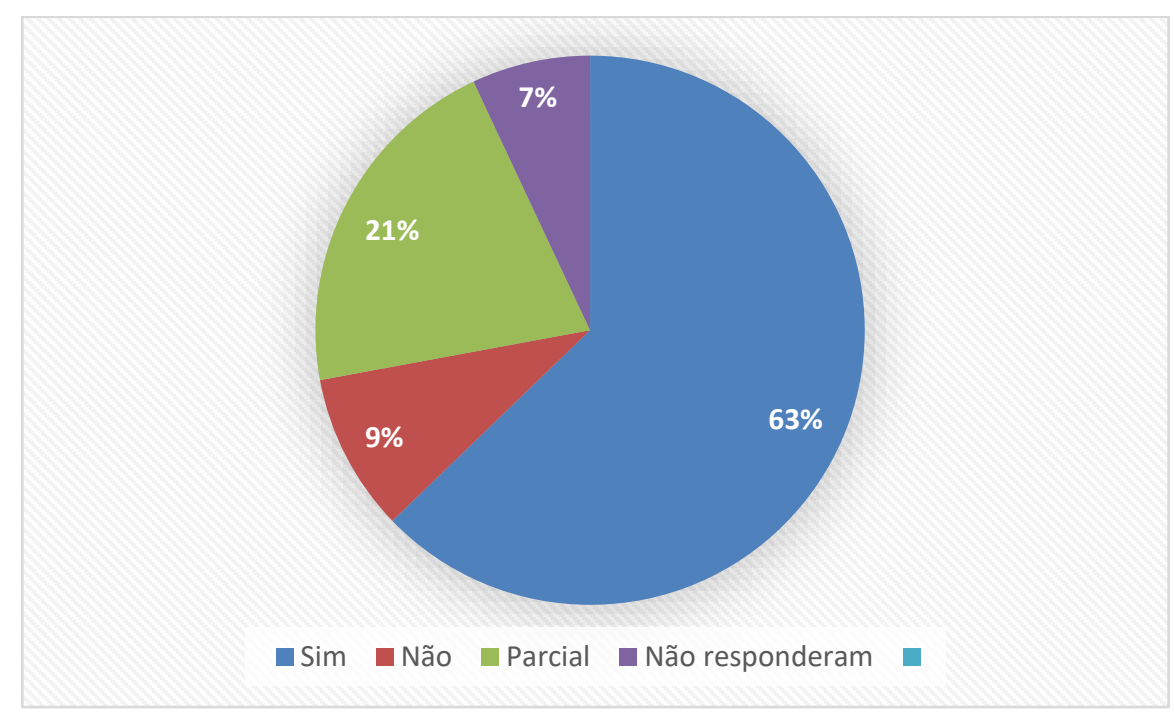

Fonte: Autores (2015). 


\section{Revista Docência e Cibercultura}

A categoria (3) "Dados do bibliotecário do Polo da UAB" investiga dados pertinentes ao biblotecário: saber se existem bibliotecários atuando nos polos; qual a formação do profissional e/ou responsável pela biblioteca do polo.

Nesta Categoria foram analisados: (a) capacidade técnica (formação profissional); (b) tempo de dedicação nos polos de EaD nos cursos da UAB; (c) suporte dado aos estudantes, tutores e professores da UAB.

Foram agrupadas 2 questões, para identificar a existência do bibliotecário e de outros profissionais não bibliotecários atuando na biblioteca dos polos da UAB e assuntos pertinentes, de acordo a essa categoria (Gráfico 5).

O gráfico 5 representa a presença do bibliotecário e/ou responsável pela biblioteca, que de acordo com as respostas dos coordenadores respondentes, a presença do bibliotecário é de 7\%. 58\% afirmaram que nas bibliotecas dos polos nos quais atuam, não existe o profissional bibliotecário, mas alguém respondendo pela biblioteca.

\section{Gráfico 5 - Presença do bibliotecário no Polo da UAB}

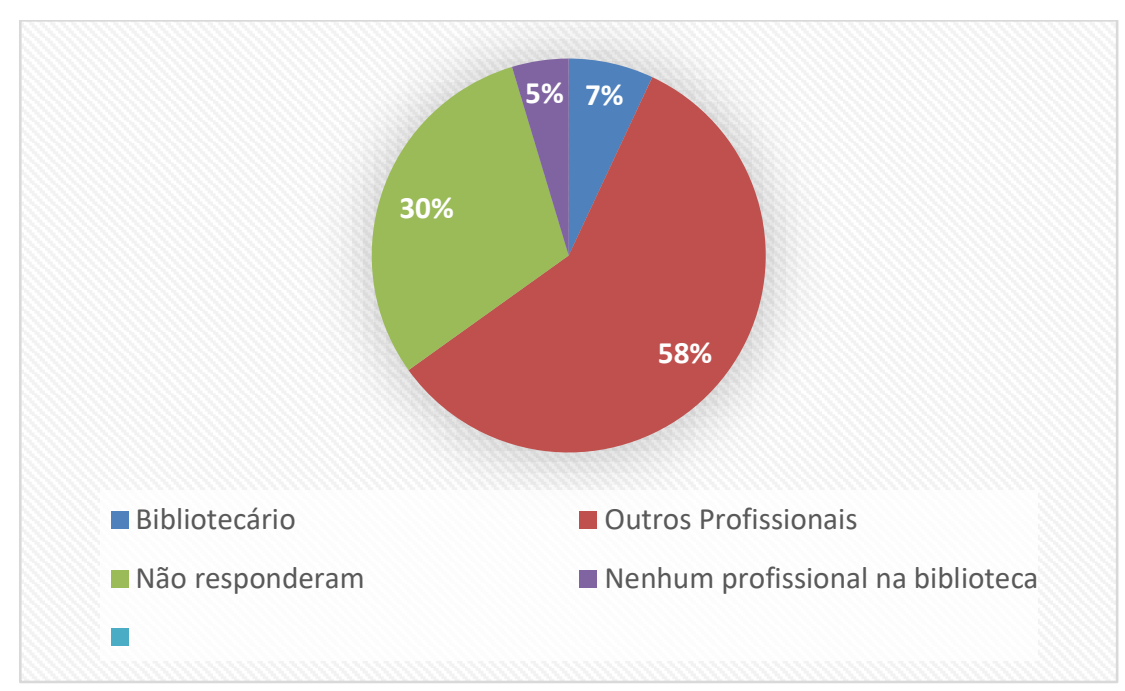

Fonte: Autores (2015)

Para uma análise mais aprofundada foram confrontadas as respostas da questão que trata da existência do bibliotecário nos polos, com as respostas da questão que trata da formação dos responsáveis pelas bibliotecas dos polos pesquisados. Constatou-se que o percentual da presença do bibliotecário nos polos é de apenas 7\%. 58\% são profissionais com formação diversas, $30 \%$ não responderam a pergunta e 5\% informaram que não existe nenhum profissional prestando serviços nas bibliotecas dos Polos onde atuam. 


\section{Revista Docência e Cibercultura}

Constata-se no gráfico 5 a presença mínima do bibliotecário nos polos da UAB, para oferecer aos estudantes, tutores e docentes um serviço de qualidade, ao acesso da informação, a organização e tratamento da informação de forma apropriada. Isso aponta que a falta de bibliotecários nos polos da UAB está em desacordo às exigências legais e norteadores do Sistema UAB, assim como, contraria a Lei $n{ }^{\circ}$ 9.674/1998, no seu Art. 4o "O exercício da profissão de Bibliotecário, no âmbito das pessoas jurídicas de direito público e privado, é privativo dos Bacharéis em Biblioteconomia". Nesse sentido, justifica-se a necessidade de contratação desse profissional especializado para desempenhar funções específicas e outras que vão além de sua formação acadêmica e da conceituação de sua profissão, pois os avanços das estruturas da informação que trafegam nas TIC necessitam de profissionais preparados para trabalharem na EaD.

\section{Gráfico 6 - Permanência do profissional não bibliotecário responsável pela biblioteca no Polo da UAB}

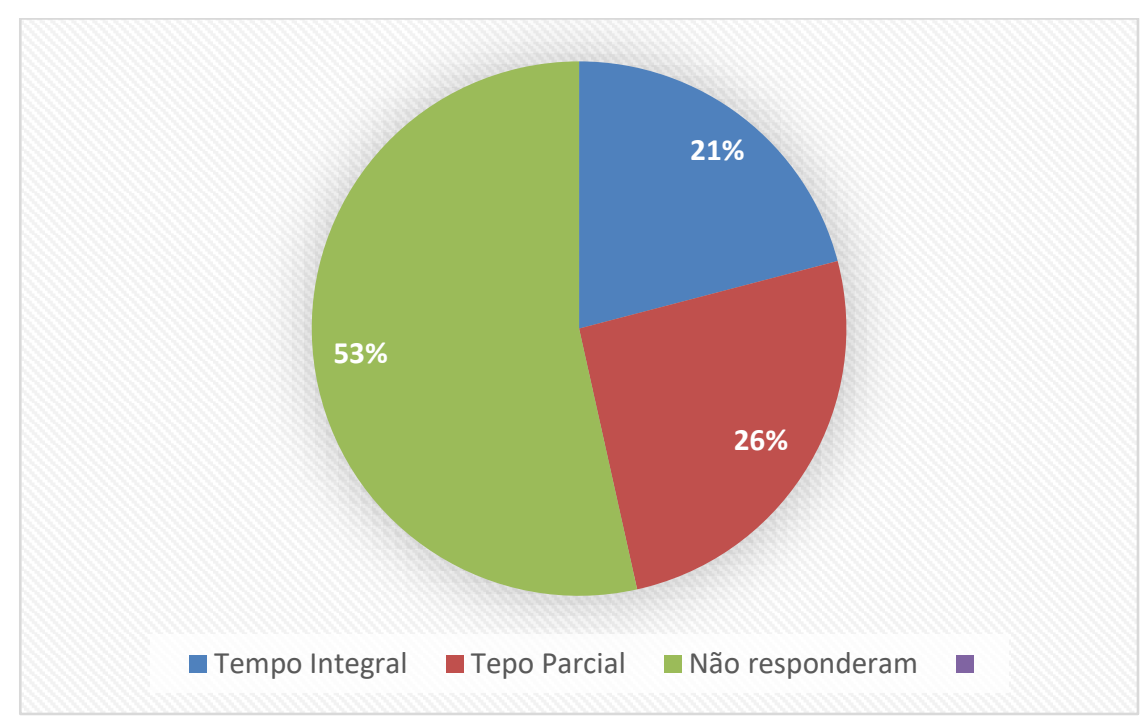

Fonte: Autores (2015)

O Gráfico 6, se refere ao tempo de permanência dos responsáveis pelas bibliotecas dos polos da UAB para atendimento aos estudantes, tutores e docentes. Mostra que $21 \%$ dos responsáveis estão em tempo integral, $26 \%$ em tempo parcial e $53 \%$ não responderam a pergunta. Houve limitação para uma análise mais detalhada da presença do profissional responsável pela biblioteca dos polos, pelo fato de um percentual muito grande de coordenadores não ter respondido a esse dado. 


\section{Revista Docência e Cibercultura}

O objetivo dessa questão foi investigar o horário de funcionamento das bibliotecas dos polos da UAB e se estão adequados para atender às necessidades dos cursos e dos estudantes, tutores e docentes que necessitam do acesso a informação, principalmente os estudantes trabalhadores, que precisam ser atendidos quando estiverem com horário disponível. Se possível, a biblioteca deve funcionar durante todos os dias úteis da semana, inclusive no final de semana, para estar em conformidade com os RQESD.

\section{Considerações Finais}

Neste estudo, investigamos o acesso a informação, serviço ofertado pelas bibliotecas nos polos da $\mathrm{UAB}$ aos estudantes, tutores e docentes, se tem bibliotecários nos polos atuando em conformidade com a proposta do Sistema UAB e com a legislação vigente. Procuramos saber em que medida a biblioteca dos polos se encontra estruturada para o acesso às informações e para atender seus usuários da $\mathrm{EaD}$ e, se o bibliotecário atua e desenvolve um trabalho especializado de qualidade para atender as necessidades do público inserido nos cursos ofertados a distância.

Em relação à existência de bibliotecário, o estudo demonstrou que a situação atual aponta para a quase ausência desse profissional. Quanto a estrutura das bibliotecas nos polos da UAB evidenciou que a situação até o momento presente é adequada.

Respondendo a questão central do estudo sobre a existência de bibliotecas, bibliotecários e serviços de acesso à informação nos polos da $\mathrm{UAB}$, em conformidade com os RQESD e com os Instrumentos de Avaliação do MEC para Bibliotecas, os resultados encontrados ressaltam que em $95 \%$ dos polos da UAB existe biblioteca física, o que se ajusta a proposta do Sistema UAB e com os RQESD.

Os resultados encontrados sobre o bibliotecário, 63\% das respostas afirmam que nos polos não tem bibliotecário, são outros profissionais que atuam na biblioteca, se acrescidos dos $30 \%$ dos que não responderam ao dado formação, se tem um percentual de $93 \%$. É um resultado não satisfatório e preocupante além de não estar adequado com à proposta do Sistema UAB, com os RQESD, com a legislação vigente em EaD e com a Lei nº 4.084/1962, complementada com a Lei $n^{\circ}$ 9.674/1998 que regulamenta o exercício da profissão de bibliotecário. A ausência do bibliotecário compromete a oferta de serviços adequados.

A ausência de bibliotecário, mediador entre o usuário e a informação, pode comprometer a oferta de serviços relevantes de gestão e de disseminação de informações e 


\section{Revista Docência e Cibercultura}

estratégicas para a tomada de decisões, quer seja no ensino-aprendizagem bem como na elaboração e efetivação de projetos e ações voltados para o desenvolvimento regional e social.

Os envolvidos, as IPES, os estados e os munícipios que são responsáveis pela manutenção dos polos, entendendo as mudanças tecnológicas e apoiando as bibliotecas dos polos da UAB, podem contribuir para que essas cumpram seus objetivos, disponibilizando informações e conhecimento que contribuam para com a formação acadêmica dos estudantes da EaD.

Este estudo poderá contribuir como instrumento para que as IPES continuem implementando ações, visando uma UAB forte e dinâmica, oferecendo serviços de qualidade e satisfatórios aos estudantes que participam de cursos na modalidade EaD.

Sugerimos algumas recomendações para promover melhorias no processo de estruturação das bibliotecas dos polos do Sistema UAB: criação de comissão para conscientização nos municípios atendidos pela $\mathrm{UAB}$, composta por representantes municipais e estaduais, bibliotecário, coordenadores dos polos de $\mathrm{EaD}$ e representantes estudantis; padronizar à aquisição e distribuição do acervo para as bibliotecas dos polos de EaD com apoio dos coordenadores, docentes e tutores envolvidos no processo; criação de rede de compartilhamento de informações dos acervos eletrônicos entre as IPES e as bibliotecas dos polos de $\mathrm{EaD}$, por meio de parcerias, com o objetivo de disseminar as informações contidas nos periódicos eletrônicos, bases de dados e acervos digitais; implantar cursos de capacitação para auxiliares de bibliotecas, promovido pelas bibliotecas-sede; ampliar os serviços disponibilizados pelas bibliotecas à comunidade local, tanto em meio virtual quanto presencial, de forma a contribuir para o desenvolvimento social-cultural da região; criação de modelo padrão de biblioteca para os polos da UAB/UFAL para assegurar a qualidade dos serviços prestados.

Com isso, acreditamos ser possível sensibilizar e fazer com que os envolvidos com o Sistema UAB direcionem um olhar diferenciado para a biblioteca e o bibliotecário no contexto dos polos de $\mathrm{EaD}$.

\section{Referências}

ABDELRAHMAN, O. H. A basic hybrid library support model to distance learners in Sudan. Journal of Librarianship and Information Science, v. 44, n. 1, p. 19-26, 2012. Disponível em: <http://lis.sagepub.com/content/44/1/19.short>. Acesso em: 22 maio 2014. 
ANOHINA, A. Analysis of the terminology used in the field of virtual learning. Journal of Educational Technology \& Society, Athens, v. 8, n. 3, p. 91-102, 2005. Disponível em: $<$ http://www.ifets.info/journals/8_3/9.pdf>. Acesso em: 15 jul. 2014.

BARDIN, L. Análise de conteúdo. São Paulo: Edições 70, 2011.

BLATTMANN, U. Modelo de gestão da informação digital online em bibliotecas acadêmicas na educação a distância: biblioteca virtual. Tese (Doutorado em Engenharia de Produção) - Universidade Federal de Santa Catarina, 2001. Florianópolis, 2001. Disponível em: <http://teses.eps.ufsc.br/defesa/pdf/2916.pdf>. Acesso em: 12 jul. 2014.

BLATTMANN, U.; BELLI, M. J. As bibliotecas na educação a distância: revisão de literatura. Revista Online Biblioteca Prof. Joel Martins, Campinas, v. 11, n. 1, 2000.

; DUTRA, S. K. W. Atividades em bibliotecas colaborando com a educação a distância. São Paulo: Associação Paulista de Bibliotecários, 1999.

BRASIL. Decreto $\mathrm{n}^{\circ}$ 5.622, de 19 de dezembro de 2005. Regulamenta o art. 80 da Lei no ${ }^{0}$ 9.394, de 20 de dezembro de 1996, que estabelece as diretrizes e bases da educação nacional. Diário Oficial [da] República Federativa do Brasil. Brasília, DF, 20 dez. 2005a. Disponível em: <http://www.planalto.gov. br/ccivil_03/_Ato 2004-2006/2005/Decreto/D5622.htm>. Acesso em 29 ago. 2014.

Decreto $\mathrm{n}^{\circ}$ 5.773, de 9 de maio de 2006. Dispõe sobre o exercício das funções de regulação, supervisão e avaliação de instituições de educação superior e cursos superiores de graduação e sequenciais no sistema federal de ensino. Diário Oficial [da] República Federativa do Brasil. Brasília, DF, 10 maio 2006a. Disponível em: <http://portal.mec.gov.br/seed/arquivos/pdf/legislacao/decreton5773 1.pdf>. Acesso em: 29 ago. 2014.

Decreto n. 5.800, de 8 de junho de 2006. Dispõe sobre o Sistema Universidade Aberta do Brasil. Diário Oficial [da] República Federativa do Brasil. Federativa do Brasil. Brasília, DF, 9 jun. 2006b. Disponível em: <http://www.planalto. gov.br/ccivil_03/_Ato20042006/2006/Decreto/D5800.htm>. Acesso em: Acesso em: 25 jul.2014. 
BRASIL. Edital n ${ }^{\circ} 1$ de 16 de dezembro de 2005. Chamada pública para seleção de polos Municipais de apoio presencial e de cursos superiores de instituições federais de ensino superior na modalidade de educação a distância para o Sistema Universidade Aberta do Brasil UAB. Diário Oficial [da] República Federativa do Brasil, Brasília, DF, 20 dez. 2005b. Disponível em: <http://www.uab.capes.gov.br/ images/stories/downloads/ editais/editaluab1.pdf>. Acesso em: 21 ago.2014.

Lei n $^{\circ} 4.084$, de 30 de junho de 1962. Dispõe sobre a profissão de bibliotecário e regula seu exercício. Diário Oficial da União, Brasília, DF, 2 jul. 1962. Disponível em: http://www.planalto.gov.br/ccivil_03/leis/1950-1969/L4084.htm. Acesso em: 21 ago. 2014.

BRASIL. Lei n ${ }^{\circ}$ 9.394, de 20 de dezembro de 1996. Estabelece as diretrizes e bases da educação nacional. Diário Oficial [da] República Federativa do Brasil, Brasília, DF, 23 dez. 1996. Disponível em: <http://www.planalto.gov.br/ccivil03/leis/19394. htm>. Acesso em: 29 ago. 2014.

BRASIL. Ministério da Educação. Portaria Normativa nº 2, de 10 de janeiro de 2007 Dispõe sobre os procedimentos de regulação e avaliação da educação superior na modalidade a distância. Diário Oficial [da] República Federativa do Brasil, Brasília, DF, 24 de fev. 2007b. Disponível em: <http://portal.mec.gov.br/seed/arquivos/pdf/legislacao/ portaria 2.pdf >. Acesso em: 25 ago. 2014.

Ministério da Educação. Coordenação de Aperfeiçoamento de Pessoal de Nível Superior. Portaria $\mathrm{n}^{\circ} 883$, de 16 de setembro de 2009, estabelece as diretrizes nacionais para o funcionamento dos Fóruns Estaduais Permanentes de Apoio à Formação Docentes criados pelo Decreto $n^{\text {0 }} 6.755$ de 29 de janeiro de 2009b. Diário Oficial [da] República Federativa do Brasil, Brasília, DF, 17 de set. 2009. Disponível em: <http://portal.mec.gov.br/dmdocuments/port883.pdf〉. Acesso em: 25 jan. 2015.

Ministério da Educação. Secretaria de Educação a Distância. Referenciais de Qualidade para Educação superior a Distância. Brasília, DF, 2007c. Disponível em: <http://portal.mec.gov.br/seed/arquivos/ pdf/legislacao/refead1.pdf>. Acesso em: 31 ago. 2014 


\section{Revista Docência e Cibercultura}

Mistério da Educação. Sistema Nacional de Avaliação da Educação Superior.

Instrumento de avaliação de cursos de graduação: bacharelado e licenciatura. Brasília, DF, 2010.

Ministério do Trabalho e Emprego. Classificação Brasileira de Ocupações. 2612: profissionais da informação. Brasília, DF, 2002. Disponível em: <http://www.mtecbo. gov.br/cbosite/pages/pesquisas/ResultadoFamiliaDescricao. jsf >. Acesso em: 20 mar. 2015.

CERVERA, A. Document management in the open University of Catalunya (UOC) classrooms. D-Lib Magazine, v. 16, n. 7-8, 2010. Disponível em: < http://www.scopus.com/inward/record.url?eid=2-s2.0-77956410641\&partnerID= 40\&md5=3402de3dd6d55a55a115cbf9721b9444> . Acesso em 20 maio 2014.

GARCEZ, E. M. S. Biblioteca híbrida: um novo enfoque no suporte à educação a distância. Ciência da Informação, Brasília, v. 31, n. 2, p. 44-51, maio/ago. 2002.

GOMES, R. A Análise de dados em pesquisa qualitativa. In: MINAYO, M. C. S. Pesquisa social: teoria, método e criatividade. 14. ed. Petrópolis: Vozes, 1998.

LEVACOV, M. As bibliotecas virtuais: problemas, paradoxos, controvérsias. Intexto, Porto Alegre, v. 1, n. 1, p. 1-15, jan./jun. 1997.

LITTO, F. M. Recursos educacionais abertos. In: ; FORMIGA, M. Educação a distância: o estado da arte. São Paulo: Pearson, 2009. p. 304-305.

MARCHIORI, P. Z. "Ciberteca" ou biblioteca virtual: uma perspectiva de gerenciamento de recursos de informação. Ciência da Informação, Brasília, DF, v. 26, n. 2, p. 5, 1997. Acesso em: 22 out. 2014.

MOORE, M.; KEARSLEY, G. A educação a distância: uma visão integrada. São Paulo: Thompson Learning, 2007.

MUELLER, S. P. Universidade e informação: a biblioteca universitária e os programas de educação a distância - uma questão ainda não resolvida. DataGramaZero - Revista de Ciência da Informação, Rio de Janeiro, v.1, n. 4, ago. 2000. Disponível em: 
<http://repositorio.bce.unb.br/bitstream/10482/991/3/ARTIGO_Universidade Informaca.pdf>. Acesso em: 22 mar. 2015.

NOAH, C. B.; BRAUN, L. W. The browsable classroom: an introduction to e-learning for librarians. Nova York: 2002.

SOUTO, L. F. Inserção do bibliotecário na equipe multidisciplinar de ensino a distância: crítica ao princípio de autonomia para aprendizagem e busca de informações. Revista ACB: Biblioteconomia em Santa Catarina, Florianópolis, v. 15, n. 1, p. 54-70 jan./jun. 2010.

UNIVERSIDADE ABERTA DO BRASIL. Coordenação de Aperfeiçoamento de Pessoal de Nível Superior. UAB, o que é a Universidade Aberta do Brasil. Disponível em: <http://uab.capes.gov.br/index.php/sobre-a-uab/o-que-e>. Acesso em: 16 ago. 2013.

VALENTIM, M. L. P. (Org.). O profissional da informação: formação, perfil e atuação profissional. São Paulo: Polis, 2004. 